\title{
CK20-Nachweis im Knochenmark: Menetekel für Blasenkrebs-Patienten
}

\begin{abstract}
Um disseminierte Tumorzellen zu entdecken, werden zunehmend auch PCR-Techniken eingesetzt. Das Protein Cytokeratin-20 (CK20) gilt als verlässlicher Marker für Blasenkarzinomzellen, die ins Knochenmark abgewandert sind. Ein CK20-positiver Knochenmarkbefund verheißt dabei für die Prognose der Patienten nichts Gutes, wie eine deutschen Pilotstudie zeigt.
\end{abstract}

In einer prospektiven Studie mit $51 \mathrm{~Pa}$ tienten mit einem Hochrisiko-Urothelkarzinom wurde untersucht, welchen prognostischen Einfluss ein CK20-positiver Knochenmarkbefund hat. Bevor sich die Patienten einer radikalen Zystektomie unterzogen, wurden Knochenmarkproben aus dem Beckenkamm entnommen. CK20-positive Zellen im Knochenmark wurden mittels Reverse Transkriptase-Polymerase-Kettenreaktion (RT-PCR) nachgewiesen. CK20 ist ein Filamentprotein, das normalerweise im gastrointestinalen Epithel, in Merkelzellen der Haut und im Urothel gebildet wird, aber in peripheren Blut, Knochenmark oder Lymphknoten nicht zu finden ist.

Der Blasenkrebs hatte sich bei zehn Patienten bereits in die Lymphknoten ausgebreitet. Bei 16 Patienten (31\%) wur- den im Knochenmark CK20-positive Zellen entdeckt. Betroffen waren Patienten in allen Tumorstadien. Die CK20positiven Patienten hatten deutlich schlechtere Überlebenschancen als die CK20-negativen:

1. Ein progressionsfreies Überleben erreichten nach sieben Jahren nur 35,2\% im Vergleich zu 64,0\% in der Gruppe ohne CK20-Befund ( $p=0,007)$. Die mittlere progressionsfreie Überlebenszeit betrug 13,5 Monate vs. mehr als 68,6 Monate.

2. Die tumorspezifische Überlebensrate nach sieben Jahren betrug 46,9\% gegenüber $70,2 \%(p=0,012)$. Die mittlere tumorspezifische Überlebenszeit lag bei 19,4 Monaten vs. mehr als 97 Monaten.

3. Nach sieben Jahren lebten noch $37,5 \%$ vs. $65,7 \%$ der Patienten $(p=0,006)$. Die
Gesamtüberlebenszeit war im Mittel 18,4 Monate vs. mehr als 97 Monate.

In einer multivariaten Cox-Regressionsanalyse von prognostisch relevanten Faktoren erwiesen sich nur die Lymphknotenbeteiligung und der CK20-Status als unabhängige Vorhersageparameter für alle drei Überlebensendpunkte.

Der Nachweis von CK20-Zellen im Knochenmark war auch bei den Patienten ohne Lymphknotenbefall ein schlechtes Zeichen: Nach sieben Jahren lebten von ihnen noch $46,2 \%$ im Vergleich zu 75,0\% der CK20-negativen Patienten $(\mathrm{p}=0,014)$.

Fazit: Blasenkarzinompatienten mit disseminierten CK20-positiven Zellen im Knochenmark sind dieser Pilotstudie zufolge eine Hochrisikogruppe mit düsterer Prognose. Die Studienautoren um Margitta Retz von der TU München wollen den Zusammenhang jetzt in einer prospektiven, multizentrischen Studie mit größerer Fallzahl überprüfen.

Dr. Beate Schumacher

Retz M. et al. Long-term follow-up of bladder cancer patients with disseminated tumour cells in bone marrow. European Urology 2011; 60: 231-38

\section{Gesunde zum PSA-Test}

Das PSA-Screening gilt seit Langem als Standard in der Prostatakrebsfrüherkennung. Umso enttäuschender sind bisher die Zahlen zur Mortalitätsreduktion. Womöglich nützt das Screening nur gesunden Männern, wie eine Subgruppenanalyse vermuten lässt.

n den USA ist der Test auf das prostataspezifische Antigen (PSA) seit Langem verbreitet, er hat jedoch bislang wenig Auswirkungen auf die prostatakrebsspezifische Mortalität gezeigt. Um in neun Jahren einen Todesfall durch ein Prostatakarzinom zu verhindern, müssen 48 im PSA-Test aufgefallene Männer mit den gängigen Interventionen - radikale Prostatektomie, Bestrahlung mit oder ohne hormonale Therapie - behandelt werden. Diese Zahl könnte deshalb so hoch sein, weil das Prostatakarzinom üblicherweise erst in höherem Alter diagnostiziert wird: Die Männer sterben, bevor sie dem Krebs zum Opfer fallen.
Wenn dem so ist, müsste der Nutzen des Screenings für Männer mit gutem Gesundheitszustand größer sein. Diese Annahme wurde retrospektiv anhand der Daten der US-amerikanischen PLCOStudie (Prostate, Lung, Colorectal and Overian) an 76.693 Männern untersucht. Der Interventionsgruppe war sechs Jahre lang ein jährlicher PSA-Test angeboten worden sowie vier Jahre lang eine jährliche Tastuntersuchung; bei auffälligen Ergebnissen wurde bioptiert. Die Kontrollgruppe erhielt eine normale ärztliche Betreuung - binnen sechs Jahren ging allerdings auch hier etwa jeder Zweite zum PSA-Screening.
Nach zehn Jahren waren 9.565 Todesfälle eingetreten, 164 aufgrund eines Prostatakarzinoms. Für Männer mit keiner oder geringer Komorbidität war das Risiko, an einem Prostatakarzinom zu sterben, in der Interventionsgruppe signifikant geringer als in der Kontrollgruppe (22 vs. 38 Todesfälle, Hazard Ratio [HR] 0,$56 ; \mathrm{p}=0,03$; Number needed to treat: 5). Männern mit mindestens einer signifikanten Komorbidität half die Intervention dagegen nicht (HR 1,43).

Fazit: Der Studie zufolge mindert das PSA-Screening für Männer mit guter Gesundheit deutlich das Risiko, am Prostatakarzinom zu sterben; in der Studie war das ein gutes Drittel. Christina Berndt

Crawford ED et al. Comorbidity and mortality results from a randomized prostate cancer screening trial. J Clin Oncol 2011; 29: 355-61 